\title{
El potencial de puertos pivotes en la costa del Pacífico sudamericano
}

\section{Jan Hoffmann \\ Unidad de Transporte, División de Recursos Naturales e Infraestructura, CEPAL, Santiago de Chile jhoffmann@eclac.cl}

El comercio exterior de un país está estrechamente vinculado a su ubicación geográfica, los servicios de transporte que cubren las distancias hacia los mercados y los puertos por los cuales pasa este comercio. Recientes avances en el transporte marítimo, la creciente integración económica internacional y las privatizaciones portuarias en los países del Pacífico sudamericano han llevado a crear expectativas de que surjan puertos que concentren carga nacional y de países vecinos para su posterior redistribución: los llamados puertos pivotes. La principal conclusión del presente análisis es que el potencial de puertos pivotes en la costa del Pacífico sudamericano es muy limitado. En el pasado, los países trataban de evitar que el comercio exterior de los países vecinos se beneficiase de los puertos nacionales. Hoy en día, la situación se ha revertido y los puertos tratan de competir por el comercio de los países vecinos. Esta competencia por sí sola es positiva. Sin embargo, en muchos casos se ha elevado a un nivel político que ha convertido una simple competencia interportuaria en una competencia internacional entre hipotéticos futuros puertos pivotes. En vista de las bajas probabilidades de que el establecimiento de puertos pivotes en el oeste de Sudamérica sea exitoso, podría ser más conveniente buscar una mayor coordinación regional de políticas de transporte y de inversiones en infraestructura portuaria y de transporte terrestre para fomentar la integración entre los países sudamericanos del Atlántico y del Pacífico. 


\section{I}

\section{Introducción}

Los puertos pivotes ${ }^{1}$ son puertos marítimos que concentran carga de diferentes procedencias y destinos, nacionales y extranjeros, para su posterior redistribución. ${ }^{2}$ Generan así negocios para la economía local al transportar el comercio que no es del entorno cercano al propio puerto.

El que exista o no potencial para que surjan tales puertos pivotes en la costa oeste de Sudamérica es importante tanto para la integración económica entre los países sudamericanos como para la integración de éstos con otras regiones. Por ejemplo, los servicios de transporte entre Sudamérica y los países asiáticos de la costa del Pacífico son cruciales para la participación de los países sudamericanos en el foro de Cooperación Económica del Asia-Pacífico (APEC), y los enlaces portuarios son elementos fundamentales para conectar los corredores bioceánicos con servicios de transporte marítimo.

En términos más generales, en los últimos años han aparecido muchos estudios que analizan la relación entre la geografía y el desarrollo de los países, incorporando aspectos como distancia y transporte. Radelet y Sachs (1998), por ejemplo, buscan identificar los factores determinantes de los costos del transporte y después investigan la relación entre estos costos y las tasas de crecimiento. Los resultados muestran una clara relación negativa entre ambas variables. Dada la importancia del modo marítimo dentro del transporte internacional, mejorar su eficiencia y reducir así sus costos debería formar parte de cualquier política de desarrollo.

En los últimos años la industria del transporte marítimo de líneas ha experimentado un marcado proceso de concentración, que incluye alianzas y fusiones entre empresas navieras, y un aumento del tráfico por-

\footnotetext{
${ }^{1}$ A veces se les llama también "puertos $h u b$ ", usando terminología inglesa.

2 Esta definición es independiente del grado de industrialización del puerto. También es independiente del volumen del tráfico portuario. Tratamos de evitar la palabra "megapuerto" porque no existe una definición del concepto ni tampoco es necesario su uso. La concentración de carga puede implicar uno o más modos de transporte. Si se usa únicamente el modo marítimo se habla de "tráfico de transbordo". Si la carga llega de otro país por vía terrestre y sale del puerto por vía marítima, se usa el término "tránsito".
}

tuario de trasbordo de carga en contenedores. ${ }^{3}$ A la vez, los países de América Latina están abriendo sus economías, y su comercio internacional está creciendo más rápidamente que su producto, lo que conlleva un fuerte aumento de la necesidad de servicios de transporte internacional.

Ambas tendencias - los avances en la industria del transporte marítimo y la apertura económica de los países - han contribuido a que nazcan expectativas de que los puertos puedan vender sus servicios a países vecinos. Tradicionalmente, los puertos servían casi únicamente al comercio exterior nacional, pero ahora existen posibilidades de prestar servicios además a carga cuya procedencia y destino sean extranjeros. Tales expectativas han surgido en puertos de los cuatro países sudamericanos que dan al Pacífico: Chile, Colombia, Ecuador y Perú.

Coincide que a la vez los puertos de estos cuatro países están siendo privatizados y se están buscando inversionistas para mejorar la infraestructura y productividad portuarias. A primera vista, parece entonces razonable que los gobiernos traten de buscar inversionistas no sólo para mejorar los servicios que requiere la carga nacional, sino también para generar negocios adicionales con la exportación de servicios portuarios.

La intención de ofrecer servicios portuarios al comercio de otros países es en sí el resultado de un cambio de actitud positivo. Hasta principios de los años noventa, se trataba justamente de evitar que eso sucediera. Los exportadores opinaban que la mercancía de países vecinos no debería pasar por puertos nacionales porque estaba compitiendo con los productos propios, los agricultores temían la entrada de pestes. Y las autoridades marítimas, que dependen de las armadas de guerra, se oponían a abrir sus puertos a países con los cuales tenían conflictos fronterizos.

\footnotetext{
${ }^{3}$ El transbordo implica dos movimientos portuarios: un contenedor llega en un barco, se almacena temporalmente en el puerto, y sale en otro barco. Se usa sobre todo para aprovechar economías de escala en barcos más grandes y para aumentar la frecuencia de servicios hacia un destino determinado. El tráfico de transbordo ha aumentado fuertemente en los últimos años gracias a los avances tecnológicos, el tamaño de los barcos más grandes y un incremento del uso de contenedores.
} 
Hoy, en el marco de una mayor integración política y económica regional, y de avances hacia la privatización portuaria, estas oposiciones han perdido fuerza. Los puertos están compitiendo por la carga y buscan atraer a inversionistas privados, y la ubicación geográfica en la cuenca del Pacífico crea expectativas de potenciales negocios que, en la prensa, se resumen en titulares llamativos como "Megapuertos en Sudamé- rica: A la conquista del Pacífico" (El Mercurio, 1998, p. D1).

El presente artículo analizará si existe un potencial de puertos pivotes en la costa occidental de Sudamérica, y si los puertos sudamericanos del océano $\mathrm{Pa}$ cífico cuentan con ventajas comparativas para mover el comercio entre Sudamérica y los países asiáticos del Pacífico.

\section{II}

\section{El comercio de América del Sur y}

\section{su transporte por vía marítima}

¿Cuál es la relación entre la ubicación geográfica de un país y las inversiones portuarias? A grandes rasgos, las posibles interdependencias son dos:

i) El puerto sería un medio para modificar los flujos de comercio: la mejora de los puertos podría contribuir a compensar desventajas geográficas y promover el comercio exterior nacional; el país invertiría en puertos como parte de su política comercial.

ii) Los flujos de comercio y la ubicación geográfica serían una oportunidad para generar ingresos con el suministro de servicios portuarios: los puertos podrían beneficiarse de una ubicación geográfica privilegiada y ofrecer sus servicios al comercio exterior nacional y de países vecinos; el país invertiría en puertos para exportar servicios portuarios.

Ambas motivaciones podrían desempeñar un papel relevante en el desarrollo potencial de puertos pivotes en Sudamérica. Se buscaría reducir los costos del transporte para el comercio exterior nacional, y a la vez se pretendería atraer carga adicional de países vecinos, que ayudaría al puerto a generar economías de escala y, por ende, a bajar también los costos del comercio exterior nacional.

\section{El puerto como facilitador del comercio exte- rior}

La situación geográfica y las distancias entre países, junto con la existencia de servicios de transporte que cubren estas distancias, influyen sobre las corrientes de comercio. Países más cercanos tienen más comercio bilateral que países más lejanos. Eso se explica en parte por razones históricas, políticas, culturales y lingüís- ticas, y también por los costos de transporte y el tiempo de entrega de la mercancía. Según una regresión hecha por Gallup y Sachs (1999), con cada mil kilómetros de distancia entre el país y los principales mercados, el costo de transporte se eleva en un punto porcentual del valor de la mercancía.

En 1998, el 99.75\% del volumen del comercio exterior de Argentina, Brasil, Chile, Perú y Uruguay con Asia, América del Norte y Europa se transportó por vía marítima, y sólo el $0.25 \%$ por vía aérea. $\mathrm{La}$ situación es algo diferente si se analiza el valor del comercio: dado que la mercadería de mayor valor y menor peso se transporta de preferencia por vía aérea, la participación del transporte marítimo en el comercio intercontinental alcanzó al $80.15 \%$ del valor, y la del transporte aéreo al $19.85 \%$.

En el comercio por vía marítima de los países sudamericanos se observa que Chile, Ecuador y Perú, que se hallan en la costa occidental, comercian relativamente menos con Europa que Argentina, Brasil y Uruguay, en la costa oriental (gráfico 1).

Destaca en el gráfico que estos últimos tres países tienen en conjunto 4.5 veces más comercio intercontinental por vía marítima que Chile, Ecuador y Perú. Dentro de este comercio, el intercambio de los países de la costa del Atlántico con Europa fue casi tres veces mayor que aquél con América del Norte, mientras que el de los países de la costa del Pacífico con América del Norte casi dobló aquél con Europa. Aunque en volúmenes totales los tres países del Atlántico tuvieron 3.5 veces más comercio con Asia, en términos relativos el comercio por vía marítima con Asia fue igual de importante para los países del Pacífico. 
GRAFICO
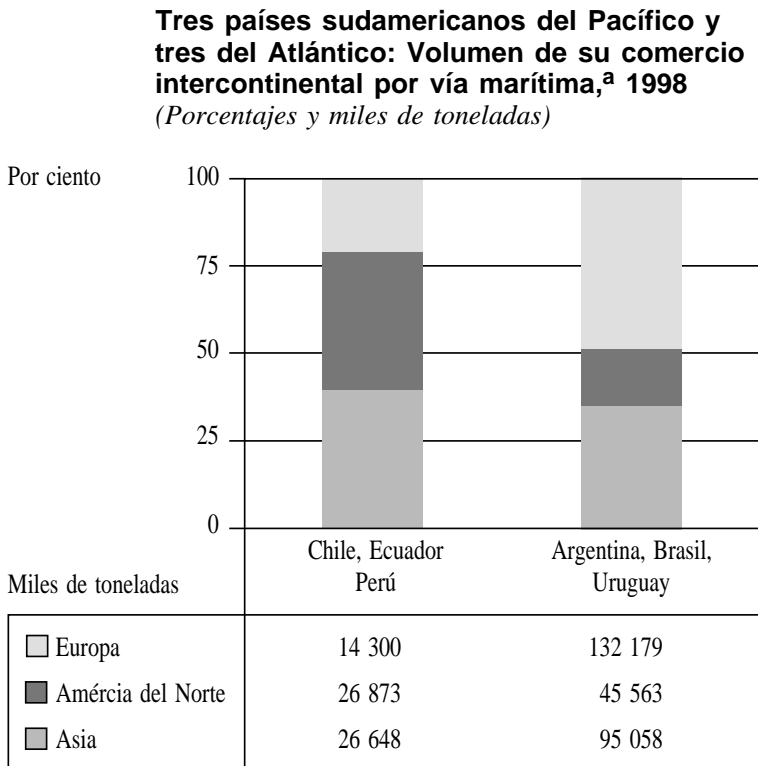

Fuente: Base de datos de transporte internacional (BTI), de la Unidad de Transporte de la CEPAL.

a Incluye importaciones y exportaciones. El comercio con Africa es menos del uno por ciento del comercio total. Los datos de Ecuador incluyen comercio por vía aérea. América del Norte incluye únicamente los Estados Unidos y Canadá. Asia incluye los países asiáticos y Australia y Nueva Zelandia.

Estos flujos de comercio por vía marítima, ¿son el resultado de las distancias y de los servicios marítimos y portuarios? Más adelante se examinarán las ventajas comparativas de puertos en ambas costas para el comercio con distintos continentes. Por ahora cabe destacar que el peso relativo del comercio intercontinental de los países examinados corresponde aproximadamente a las distancias entre las costas sudamericanas y los demás continentes. Los países del Mercosur (Argentina, Brasil y Uruguay) están más cerca de Europa que Chile, Ecuador y Perú. Para llegar a Europa, los barcos de estos últimos países tienen que cruzar el canal de Panamá, lo que acarrea costos y demoras adicionales. Ambas costas sudamericanas están aproximadamente a la misma distancia de los puertos asiáticos.

¿Se puede promover el comercio con inversiones en infraestructura portuaria? La respuesta es afirmativa, siempre y cuando esta inversión reduzca los costos y/o eleve la productividad. Tales mejoras disminuyen la "distancia económica", es decir, reducen el impacto negativo de la distancia geográfica. De las recientes y actuales privatizaciones y modernizaciones portuarias y liberalizaciones en el transporte marítimo efectuadas en los países sudamericanos se puede esperar un aumento general del comercio intercontinental.

¿Se puede promover el comercio si una región específica hace inversiones en infraestructura portuaria? En principio sí, pero probablemente no en el caso concreto de Sudamérica. Todos los puertos atienden el comercio con todos los continentes. No se ven razones para esperar cambios de dirección en los principales flujos de comercio por vía marítima hacia los diversos continentes. Una situación diferente se podría dar quizás si se modificara la infraestructura terrestre para facilitar, por ejemplo, el acceso de productos chilenos a puertos argentinos, lo que probablemente aumentaría el comercio chileno con Europa.

En resumen, hay influencia recíproca entre los flujos de comercio y los servicios de transporte internacional. Unos y otros son en parte el resultado de la ubicación geográfica de los países y las distancias hacia los principales mercados. El impacto de los flujos de comercio sobre el volumen de tráfico portuario es más fuerte que la influencia que puede tener una mayor eficiencia portuaria sobre los volúmenes de comercio.

\section{La ubicación geográfica como factor para es- tablecer puertos pivotes}

¿Tienen ventajas comparativas los puertos en la costa sudamericana del Pacífico para transformarse en puertos pivotes? ¿Cuáles son las posibilidades de concentrar carga en Chile, Colombia, Ecuador y Perú para su posterior redistribución?

La UNCTAD, en su Review of Maritime Transport (UNCTAD,1999, p. 93), señala que en Sudamérica hay puertos que están en fila para convertirse en puertos pivotes y que en la costa oeste varios puertos chilenos competirán con Callao (Perú) o Guayaquil (Ecuador). Según El Mercurio (1998), "Chile y Perú están compitiendo por establecer en sus costas megapuertos que, interconectados a corredores bioceánicos, se transformen en la puerta de la región para el Asia”. En general, muchos artículos en la prensa especializada resaltan la existencia de una "competencia intensa" entre los puertos a lo largo de la costa oeste de Sudamérica (por ejemplo, Schednet News, 1999).

En Ecuador se ha estado mencionando Manta como "puerto de transferencia internacional". Por ejemplo, en la revista CAMAE (1999) se describen sus "ventajas geográficas" y "ventajas técnicas", se subraya que "las megaempresas internacionales tienen la nece- 
sidad de establecer un puerto de esta categoría en la costa sudamericana", y se destaca su potencial para "servir como puerto de desembarque de los contenedores que vienen en barcos de gran tonelaje de países extranjeros y luego distribuirlos a puertos foráneos mediante barcos de menor tonelaje. Minimizar costos y maximizar el transporte de carga desde distintos puertos de origen tanto de Asia, Europa, EE.UU, para y desde América del Sur".

A mediados de 1998, la TDA (Trade Development Agency) de los Estados Unidos aprobó el financiamiento de un estudio de prefactibilidad por 362000 dólares al respecto. Según CAMAE (1999), "el proyecto fue considerado viable, razón por la cual la TDA lo incluye en los 125 proyectos sujetos a inversión para Sudamérica, registrándose el proyecto del Puerto de Transferencia con el código (TRAN-39) "EcuadorExpansion of the Port of Manta.", y el programa "recomendado de gastos de capital para el Puerto de Manta asciende a US\$ 135.996.240,-”.

En el Perú, es el puerto de Callao el que más expectativas tiene de convertirse en puerto pivote. Según un folleto para promover inversiones privadas, la "ubicación estratégica del Perú en Sudamérica hace que sus puertos marítimos sean altamente atractivos como potencial salida del comercio por vía marítima entre América Latina y Asia. Además, se espera que el comercio exterior de Perú y otras economías emergentes de América Latina continuará creciendo, expandiéndose así la demanda de servicios portuarios" (Comisión de Promoción de Concesiones Privadas, 1998). Otro folleto, en este caso de la Empresa Nacional de Puertos (ENAPu), resalta que "los puertos del Perú tienen una privilegiada situación geográfica en la Cuenca del Pacífico, que los convierte en puertos de enlace con los países atlánticos y mediterráneos de América del Sur, mediante una extensa red vial, ferroviaria y fluvial, apropiados para el transporte intermodal" (ENAPU, sin fecha). También en la prensa especializada se menciona que Callao "está bien ubicado para tomar carga de transbordo a lo largo de la costa oeste de Sudamérica" (Lloyds List, 1999).

De las concesiones del puerto de Callao se esperan inversiones privadas por unos 300 millones de dólares. Durante el año 1999 se rechazó un préstamo blando del gobierno japonés de 240 millones de dólares que estaba previsto para su modernización. La concesión de una terminal de contenedores, planeada para 1998 o 1999, fue postergada al año 2000. Una de las consideraciones que ha llevado a aplazarla es la duda de si se debe dividir el puerto en varios termina- les para así aumentar la competencia intraportuaria y evitar un monopolio. Por otro lado, si Callao quisiera convertirse en puerto pivote, podría ser ventajoso no dividirlo, sino tratar de ponerlo en una posición lo más competitiva posible frente a otros puertos.

En Chile, el puerto más conocido por sus aspiraciones a convertirse en puerto pivote es el de Mejillones, al norte de Antofagasta. En la prensa local se le suele denominar el "megapuerto". Ya en 1996, en un documento de trabajo del gobierno regional de Antofagasta titulado "Megapuerto de Mejillones" (Schellmann, 1996), se estipula que la bahía de Mejillones tiene "condiciones naturales sin rival" y que "el megapuerto de Mejillones es el punto neurálgico donde el hinterland compuesto por las áreas de producción del Gran Chaco se una al área de la Cuenca del Asia Pacífico". Según El Diario (1999), un representante del gobierno chileno expresó que "Mejillones está ganando la competencia por convertirse en megapuerto del Pacífico Sur".

En cuanto a montos de inversión, cuando se inició el proyecto de Mejillones se estimó una inversión total de unos 600 millones de dólares; se planeaba otorgar la concesión a finales de 1998. Después de varias postergaciones, a finales de 1999 se asignó la concesión a un consorcio de empresas chilenas que se comprometieron a invertir un total aproximado de 100 millones de dólares hasta el año 2002. En la actualidad este consorcio está buscando financiamiento en bancos comerciales e instituciones financieras multilaterales. Esta primera fase del proyecto se limita sobre todo a instalaciones para manejar el traslado de cobre, aunque en la documentación con la que se están solicitando préstamos para financiar el proyecto se sigue insistiendo en el potencial a largo plazo de atraer carga de países vecinos y del transbordo de contenedores.

Otros puertos chilenos con expectativas de atraer más tráfico de transbordo o de tránsito son sobre todo Arica, Iquique, Valparaíso, San Antonio y Talcahuano y San Vicente, aunque ninguno de ellos se suele denominar como "megapuerto". Según el diario Estrategia (1998) el alcalde de Iquique "anunció que el MOP aprobó la profundización del puerto nortino de 16 a 17 metros de calado para un nuevo frente de atraque que permita la llegada de barcos con una capacidad de 7000 contenedores. 'Los nuevos barcos del mundo se han ampliado, por tanto, Iquique no quiere quedar fuera del mercado mundial. No sólo el megapuerto que se construye en Mejillones tiene derecho a recibirlos', 
agregó”. Según la página web de la Zona Franca de Iquique (2000), ella "se encuentra situada en una privilegiada posición geográfica", y es "el más importante centro de negocios de Sudamérica, donde se conectan los mercados de la Cuenca del Pacífico y del Cono Sur de América".
En resumen, existen expectativas de puertos pivotes en todos los países sudamericanos de la costa del Pacífico. Estas se basan en el crecimiento del comercio, la integración económica regional y mundial, las privatizaciones portuarias y la percepción de las ventajas de una ubicación geográfica privilegiada.

\section{III}

\section{Centros de transbordo en el mundo}

Medida en volumen, la mayor parte de la carga marítima se transporta como granel líquido (sobre todo petróleo) y granel seco (cereales, carbón, mineral de hierro). Medida por el valor de la mercancía y de los fletes marítimos, la carga en contenedores tiene mayor importancia.

El análisis de los potenciales puertos pivotes generalmente se centra en sus posibilidades de concentrar carga en contenedores por vía marítima. Esta carga es transportada por líneas regulares. La carga a granel, en cambio, se mueve principalmente en buques charter y es menos apta para movimientos de transbordo.

\section{La decisión empresarial}

La selección de los medios de transporte para una transacción de comercio exterior obedece comúnmente a una decisión netamente comercial: el producto tiene que llegar a su destino lo antes posible, al menor costo y con el menor riesgo.

\section{a) Duración del viaje}

Una entrega rápida es cada vez más importante. El valor medio por tonelada de mercancía está aumentando, y con eso también suben los costos de capital. Aumenta la entrega justo a tiempo. La incidencia de un transbordo en la duración del viaje es mixta: por un lado, el transbordo mismo implica costos y tiempo adicional y también puede significar un desvío de la ruta para llegar al centro de transbordo. Por otro lado, es posible que en ese centro la mercancía sea colocada en un barco más rápido.

\section{b) Frecuencia}

Un viaje rápido no sirve mucho al exportador si su carga tiene que esperar muchos días o hasta semanas a que salga un servicio directo de transporte. Una de las principales ventajas de pasar por puertos pivotes es que ellos concentran carga y permiten una mayor frecuencia de salida hacia diferentes destinos.

\section{c) Costo}

El costo adicional de un transbordo puede ser en parte compensado por la ventaja de poder usar barcos más grandes con menores costos operativos. Por ejemplo, en la ruta entre Estados Unidos y Asia se estima que el uso de los barcos más grandes (llamados "postpanamax" porque no caben por el Canal de Panamá), genera una ventaja de costos de 27 dólares por contenedor para el armador, comparado con los barcos "panamax", que son los más grandes que pueden cruzar el Canal (Drewry Shipping Consultants, 1996; Hoffmann, 1999). El tamaño de los barcos que en la actualidad sirven a los puertos del Pacífico sudamericano es aproximadamente la mitad de el de los barcos panamax.

Aparte la posibilidad de concentrar carga de diferentes procedencias, el comercio mismo entre puertos de una sola ruta podría justificar el uso de barcos mayores para los tramos en medio de la ruta. Por ejemplo, suponiendo 50 contenedores para cada comercio bilateral en 12 puertos (es decir, 11 tramos), durante el último tramo el barco solamente llevará 550 contenedores (su comercio propio con los restantes 11 puertos), mientras que en el sexto tramo (entre los puertos número seis y siete) estará transportando $1800 . \mathrm{La}$ fórmula general es:

$$
\begin{gathered}
\text { Contenedores en el barco }=k(n-k) \text {, siendo } \\
n=\text { número total de puertos en la ruta, y } \\
k=\text { número del tramo }
\end{gathered}
$$

Este ejemplo refleja de manera bastante realista el caso del comercio entre la costa oeste de Sudamé- 
rica, por un lado, y Europa o América del Norte, por otro. Hay varios servicios que hacen escala en 10 a 15 puertos por viaje, y los contenedores descargados por puerto rara vez son más de 600 .

\section{d) Riesgo}

Cada transbordo implica un riesgo de daños o pérdidas de la mercancía y de atrasos por equivocaciones o huelgas. Las primas de seguro tienden a ser mayores si se usan servicios de transbordo.

\section{e) Volumen}

Las frecuencias y el tamaño de los barcos utilizados, como es obvio, están estrechamente vinculados con el volumen de las transacciones que hay que cubrir. Si éste no basta ni siquiera para llenar barcos de menor tamaño con frecuencias de por lo menos un servicio mensual, simplemente no habrá servicio directo. Se tendrá que usar servicios alimentadores (feeder) que conecten el puerto con un puerto pivote.

Relacionados con el volumen están también los balances de transporte. Si solamente hay carga en una dirección, es menos rentable establecer un servicio directo y conviene tratar de concentrar la carga en lugares donde se puedan equilibrar los flujos de comercio por vía marítima en ambas direcciones.

\section{f) El caso de Sudamérica}

Como ejemplo real que ilustra la relación entre duración de viaje y frecuencia cabe mencionar que desde el puerto de MIT, en la costa caribeña de Panamá, salen cinco diferentes servicios semanales hacia el norte de Europa, mientras que de la costa oeste de Sudamérica parten solamente tres servicios directos entre una y tres veces por mes. Estos pasan por el Canal de Panamá y uno hace una parada en MIT. En promedio, el viaje entre MIT y los puertos del norte de Europa en los cinco servicios semanales dura un día menos que el tramo Panamá-Europa de los servicios que provienen de San Antonio y Callao. En conjunto, los cinco servicios semanales que salen desde MIT conectan con más puertos diferentes en Europa.

En consecuencia si, por ejemplo, un exportador peruano no quiere esperar la salida de uno de los tres servicios directos, tal vez pueda encontrar otro servicio que lleve su carga a Panamá, y de allí aprovechar la próxima salida de uno de los cinco servicios semanales a Europa.

Dado el aumento de fusiones y alianzas entre líneas navieras, tales combinaciones de servicios son cada vez más frecuentes. En el comercio con Asia ya son varios los servicios establecidos que conectan servicios norte-sur provenientes de Sudamérica con servicios este-oeste, en Panamá o Los Angeles. Incluso, hay servicios que hacen su transbordo en el puerto panameño de MIT, que está ubicado en la costa del Caribe. De tal modo, el contenedor pasa dos veces por el canal.

En general, las conexiones entre la costa oeste sudamericana y Asia son más aptas para el uso de servicios de transbordo porque el tramo en el cual se pueden usar los barcos de mayor tamaño es mucho más largo que en los servicios hacia Europa o América del Norte.

En resumen, los puertos concentran carga para que ésta llegue a su destino al menor costo y en el menor tiempo posibles. La decisión al respecto es netamente comercial y difícilmente intervienen en ella consideraciones políticas.

\section{Centros de transbordo en la actualidad}

En la actualidad, los mayores puertos de contenedores se encuentran en Asia, Estados Unidos y Europa. Allí, los puertos de transbordo se ubican sobre todo en lugares donde se cruzan las principales rutas marítimas. Los cuadros 1 a 4 muestran el volumen del tráfico portuario en contenedores en diferentes regiones del mundo y el volumen del movimiento portuario de transbordo por regiones, ambos medidos en TEU. ${ }^{4}$

A nivel mundial, incluyendo contenedores vacíos y de transbordo, se registraron 185 millones de movimientos portuarios durante 1998. De este total, el 23\% eran movimientos de transbordo (Drewry Shipping Consultants, 1999); los porcentajes por principales

CUADRO

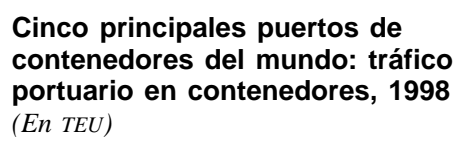

\begin{tabular}{lr}
\hline Puerto & Tráfico portuario \\
\hline Singapur & 15000000 \\
Hong Kong & 14582000 \\
Long Beach/ Los Angeles (Estados Unidos) & 7478218 \\
Kaohsiung (Taiwan, provincia de China) & 6271053 \\
Rotterdam (Países Bajos) & 6010000
\end{tabular}

Fuente: Cargo Systems, 1999.

\footnotetext{
${ }^{4}$ Twenty foot equivalent unit, una unidad equivalente a un contenedor de 20 pies.
} 
CUADRO 2

Cinco principales puertos de contenedores de América Latina y el Caribe: Tráfico portuario en contenedores, 1998 (En TEU)

\begin{tabular}{lc}
\hline Puerto & Tráfico portuario \\
\hline Buenos Aires (Argentina) & 1138000 \\
Cristóbal (Panamá) & 1117035 \\
Santos (Brasil) & 859500 \\
Kingston (Jamaica) & 670858 \\
Cabello (Venezuela) & 486774 \\
\hline
\end{tabular}

Fuente: CEPAL, 1999.

CUADRO 3

\section{Cinco principales puertos de contenedores de la costa oeste de Sudamérica: Tráfico portuario en contenedores, 1998 (En TEU)}

\begin{tabular}{lc}
\hline Puerto & Tráfico portuario \\
\hline San Antonio (Chile) & 415001 \\
Guayaquil (Ecuador) & 407434 \\
Callao (Perú) & 378013 \\
Valparaíso (Chile) & 255687 \\
Buenaventura (Colombia) & 143420 \\
\hline
\end{tabular}

Fuente: CEPAL, 1999

CUADRO 4

\section{Principales regiones de transbordo del mundo: Movimiento portuario de transbordo, 1998 (En TEU)}

\begin{tabular}{lr}
\hline Región & Movimiento portuario \\
\hline Sudeste de Asia & 13356000 \\
Lejano Oriente & 8374000 \\
Europa del Norte & 6312000 \\
Europa del Sur & 5940000 \\
Mediano Oriente & 3077000 \\
Centroamérica y el Caribe & 1994000 \\
América del Norte & 1623000 \\
Africa & 1215000 \\
Sud Asia & 1200000 \\
Sudamérica & 230000 \\
Oceanía & 112000 \\
\hline
\end{tabular}

Fuente: Drewry Shipping Consultants, 1999.

puertos de transbordo figuran en el cuadro 5 . El poco tráfico portuario de transbordo que se registra en la actualidad en Sudamérica (cuadro 6) se concentra sobre todo en Cartagena (Colombia) y Puerto Cabello (Venezuela).
CUADRO 5

Principales puertos de transbordo: Transbordo como porcentaje del tráfico portuario en contenedores, $1998^{a}$

\begin{tabular}{lc}
\hline Puerto & Transbordo (\%) \\
\hline Malta & 93 \\
Damietta (Egipto) & 90 \\
Algeciras (España) & 84 \\
Singapur & 82 \\
Gioia Tauro (Italia) & 80 \\
Kingston (Jamaica) & 75 \\
Colombo (Sri Lanka) & 70 \\
MIT (Panamá) & 70 \\
Dubai & 50 \\
Kaohsiung (Taiwán) & 43 \\
Rotterdam (Países Bajos) & 40 \\
Bremerhaven (Alemania) & 30 \\
Hamburgo (Alemania) & 30 \\
Felixstowe (Reino Unido) & 28 \\
Amberes (Bélgica) & 25 \\
Pusan (Corea) & 21 \\
Hong Kong & 18 \\
Kobe (Japón) & 15 \\
\end{tabular}

Fuente: Datos de Drewry Shipping Consultants e información directa de puertos.

a Los datos son de 1998 o del último año disponible.

CUADRO 6

Puertos sudamericanos: Transbordo como porcentaje del tráfico portuario en contenedores, 1999

\begin{tabular}{lc}
\hline Puerto & Transbordo (\%) \\
\hline Cartagena (Colombia) & 50 \\
Puerto Cabello (Venezuela) & 38 \\
Callao (Perú) & 6 \\
Buenos Aires, Pto. Nuevo (Argentina) & 3 \\
San Antonio (Chile) & 3 \\
Guayaquil (Ecuador) & 2 \\
Santos (Brasil) & 2 \\
Río de Janeiro (Brasil) & 2 \\
\end{tabular}

Fuente: Elaboración propia sobre la base de diversas fuentes.

En síntesis, los volúmenes totales de transporte de carga en Sudamérica, como también el porcentaje del tráfico de transbordo dentro de estos totales, son muy bajos en comparación con otras regiones del mundo. Sólo el 3.4\% del movimiento portuario de contenedores del mundo se registra en Sudamérica, y de este movimiento, el $3.6 \%$ es tráfico de transbordo. La región sudamericana tiene una participación de solamente $0.5 \%$ del tráfico portuario de transbordo del mundo. 


\section{Requerimientos para un puerto pivote}

a) Conexiones terrestres

Puertos pivotes que concentran carga vía terrestre son, por ejemplo, los del norte de Europa y de Estados Unidos. También Hong Kong recibe la mayor parte de su carga por vía terrestre. Para poder concentrar carga por esta vía es necesario que el puerto tenga conexiones con otros modos de transporte, sobre todo el ferrocarril, que es importante para conseguir altos volúmenes de carga. Puede ser una ventaja adicional que el puerto esté en una zona industrial que ofrece otros servicios a la carga.

\section{b) Conexiones marítimas}

El principal centro de transbordo (la carga llega y sale por vía marítima) en el mundo es Singapur. Ultimamente se está tendiendo a establecer puertos casi sin carga local, dedicados al tráfico de transbordo. Siguen además creciendo los puertos principales regionales que sirven como centro de transbordo porque cuentan con servicios marítimos internacionales, y la carga de puertos menores se tiene que trasladar a ellos para conectarse con tales servicios. La base principal para la viabilidad de tales centros es la ubicación geográfica.

En puertos donde se cruzan o se conectan rutas intercontinentales, se hace un transbordo entre barcos que sirven a dos rutas diferentes. Ejemplos son Algeciras (ruta Africa-Europa con ruta América del NorteEuropa-Asia), Jamaica y Panamá (ruta SudaméricaAmérica del Norte-Europa con ruta Europa-América del Norte-Asia), y Singapur (ruta Europa-Asia-América del Norte con ruta Australia-Europa). En Gioia Tauro, Malta y Dubai se realizan también transbordos entre diferentes servicios paralelos que conectan Norteamérica, Europa y Asia. Estos puertos funcionan con o sin carga del entorno local.

Algunos puertos conectan un mercado local con una ruta internacional que pasa por la región. Ejemplos son Colombo (subcontinente indio), Gioia Tauro y Malta (Mar Mediterráneo), Jamaica y Panamá (Caribe, Centroamérica, costa oeste de Sudamérica), Miami (Caribe) y Singapur (sudeste de Asia). Estos puertos funcionan con o sin carga del entorno local propio.
Se tiende a concentrar carga de islas y países vecinos en puertos que están ubicados en puntos finales de rutas internacionales. Ejemplos son Gotemburgo (conecta con puertos de Escandinavia), Puerto España (con otros puertos del Caribe), San Antonio (con puertos del sur de Chile), Buenos Aires (con puertos fluviales de la Hidrovía). En estos casos suele tratarse de puertos principales regionales cuya carga proviene en su mayoría del entorno local y no se les suele denominar "puertos pivotes" porque el tráfico de transbordo tiende a constituir un porcentaje bajo de su tráfico portuario total.

Obviamente, se pueden hacer transbordos con diferentes propósitos en cada puerto pivote. Exportadores e importadores en regiones del tradicional tráfico norte-sur generalmente tienen a su disposición servicios directos hacia los principales mercados en Europa, América del Norte y Asia, y también cada vez más servicios con al menos un transbordo. Ejemplos son Australia (con transbordo en Singapur), India (con transbordo en Sri Lanka), Africa oriental (con transbordo en el medio oriente), Africa occidental (con transbordo en Algeciras) y Sudamérica (con transbordo en Jamaica, Panamá y puertos de América del Norte).

Zohil y Prijon (1999) analizaron la relación entre el volumen de tráfico portuario generado en el propio puerto, la ubicación geográfica y el volumen de tráfico de transbordo para el Mar Mediterráneo. Concluyen que "los volúmenes de tráfico de transbordo en un puerto son una función lineal del volumen de tráfico portuario, y una función lineal inversa de la distancia de la línea principal de tránsito". En otras palabras, los barcos tienden a preferir puertos para los cuales ellos tienen carga local y aprovechar que ya están allí para realizar movimientos de transbordo. Cuanto menos desvío de ruta principal implique la escala, más alta es la probabilidad de que se la elija como centro de transbordo.

En resumen, para poder convertirse en pivote un puerto tiene que contar con amplias conexiones de transporte terrestre, estar ubicado en un lugar donde se conectan o cruzan rutas marítimas, o contar con altos volúmenes de carga que se generen en su entorno cercano. Ninguna de estas condiciones se dan en los puertos del oeste de Sudamérica con la misma amplitud que en los puertos pivotes ya existentes en el mundo. 


\section{IV}

\section{Servicios marítimos en Sudamérica}

¿Cuáles son las características de las líneas regulares que ofrecen servicios de transporte marítimo en Sudamérica? ¿Cómo se comparan los servicios de la costa oeste con los de la costa este? ¿Cuáles son las distancias que tiene que cubrir un servicio directo de un buque charter? Es preciso analizar estos interrogantes para poder determinar si es posible concentrar carga proveniente de los países de Sudamérica, y dónde, y si los puertos del lado del Pacífico tienen ventajas comparativas frente a los del lado del Atlántico.

\section{Servicios de líneas regulares}

\section{a) Comparación entre la costa este y la oeste de Sudamérica}

Si se comparan los servicios de líneas marítimas regulares que atienden a los puertos sudamericanos de las costas del Pacífico y del Atlántico (cuadro 7), así como las opciones disponibles para los exportadores e importadores de los países sudamericanos, se pueden hacer las observaciones que se exponen a continuación.

Hay casi dos veces más puertos con salidas de líneas marítimas en la costa este que en la oeste de Sudamérica. Desde los puertos orientales salen 56\% más servicios regulares que desde los principales puertos occidentales. Son también más empresas las que conjuntamente ofrecen estos servicios, y lo hacen con una mayor frecuencia.

Desde el lado oriental se llega antes a la costa este de los Estados Unidos, a Europa y al sudeste asiático (Singapur). Desde ambas costas la duración del viaje hacia el continente asiático (Hong Kong) es aproximadamente la misma. Desde el lado occidental se llega antes a Japón y también a la costa oeste de los Estados Unidos. De hecho, no existen servicios regulares directos entre Los Angeles y los países del Mercosur. Hay servicios regulares que hacen un transbordo en Puerto Cabello (Venezuela).

En la costa este se logran mayores economías de escala: se mueven en total casi dos veces más contenedores. Cada servicio regular mueve aproximadamente $35 \%$ más contenedores. Los barcos que se usan son de mayor tamaño. Hay servicios que usan barcos sin grúas propias, lo que implica un ahorro de costos, ya que no hace falta transportar peso y capital ocioso durante el viaje. Dado que en el lado oeste la mayoría de los puertos aún no tienen grúas especializadas para mover contenedores, es imprescindible que los servicios que atienden esta costa lleven sus propias grúas.

Ambas costas tienen superávit de contenedores en su comercio con Asia, y déficit en su comercio con América del Norte. En total, el comercio en contenedores de Sudamérica es aproximadamente equilibrado.

b) Comparación de los servicios desde las costas este y oeste de Sudamérica hacia otras regiones Un análisis más detallado de las distintas regiones de comercio revela que en ambas costas el peso relativo de los servicios de transporte marítimo hacia Asia es aproximadamente el mismo. La diferencia principal es la predominancia de servicios hacia América del Norte en la costa occidental, y la predominancia de servicios hacia Europa en la costa oriental. Cada día salen 4.5 veces más barcos con destino a Europa desde puertos del Atlántico que desde puertos del Pacífico. El lado atlántico también tiene un $32 \%$ más de salidas hacia Asia. Desde el Pacífico hay 13\% más salidas hacia América del Norte. El resultado es parecido, si se compara el número total de servicios. El gráfico 2 muestra la suma simple de servicios de todos los puertos de cada costa sudamericana hacia las tres regiones de destino. Los servicios que van desde un puerto sudamericano hacia dos regiones de destino (por ejemplo, primero Miami y después Hamburgo) se incluyen en ambas categorías. El coeficiente de correlación simple entre el número de servicios (gráfico 2) y el número de salidas portuarias (cuadro 7) es $+99 \%$.

A esta comparación cuantitativa hay que agregar otro aspecto, la frecuencia de los servicios. Desde puertos de todos los países considerados salen servicios semanales hacia Asia y América del Norte. Desde Chile y Perú, la máxima frecuencia de servicios hacia Europa es solamente cada diez días, mientras que desde Argentina y Brasil hay líneas que salen cada cinco días.

En la ruta hacia Europa, los puertos de la costa oriental tienen una clara ventaja sobre los de la costa occidental. Exportadores e importadores que tienen acceso a puertos en ambas costas deberían optar por los del Atlántico.

Para servicios hacia la costa oeste de América del Norte, los puertos del Pacífico tienen ventaja, ya que no se registran servicios regulares directos entre la 
CUADRO 7

Sudamérica: Servicios de líneas marítimas regulares en Sudamérica, costa del Pacífico (oeste) y costa del Atlántico (este)a

\begin{tabular}{l}
\hline \\
Puertos: número de puertos con servicios \\
regulares al 1 de enero del $2000^{c}$
\end{tabular}

enero del $2000^{\circ}$

Puertos principales: número de servicios regulares al 1 de enero del $2000^{c}$

Servicios: número total de salidas de barcos en cada costa, por mes, al 1 de enero del $2000^{\circ}$

Movimiento por servicio: Estimación del número promedio de TEU movidos anualmente por servicio ${ }^{\mathrm{d}}$

Viajes: duración mínima de viaje desde principales puertos sudamericanos al 1 de enero del 2000.

Frecuencias: número de días entre salidas por cada servicio directo. Promedio ponderado por puerto al 1 de enero del 2000 (ejemplo: un servicio semanal daría el número 7.0).

Empresas navieras: número de empresas navieras que ofrecen servicios de línea al 1 de enero del $2000^{\circ}$

Barcos: tamaño máximo de barcos al 1 de enero del 2000

Comercio en contenedores: total movimientos marítimos, importaciones y exportaciones, en miles de TEU en 1998. Incluye servicios no regulares.

Balances: movimientos marítimos en TEU; relación exportación/ importación, en 1998.

\section{Costa oeste: Chile, Colombia ${ }^{b}$}

Ecuador, Perú

Total 13: Chile 7, Colombia 1, Ecuador 2, Perú 3

San Antonio (Chile) 20 Callao (Perú) 20

Total: 356

Hacia Asia: 74

Hacia América del Norte: 221 Hacia Europa: 61

Todos servicios: 9195 Hacia Asia: 8708

Hacia América del Norte: 8093 Hacia Europa: 13125

San Antonio - Singapur: 36 días San Antonio - Hong Kong: 33 días San Antonio - Yokohama: 26 días San Antonio - Nueva York: 19 días San Antonio - Hamburgo: 31 días Callao - Singapur: 34 días

Callao - Hong Kong: 25 días Callao - Yokohama: 21 días Callao - Nueva York: 14 días

Callao - Hamburgo: 25 días

San Antonio - Asia: 10.2 San Antonio - Am. del Norte: 11.0 San Antonio - Europa: 13.8 Callao - Asia: 10.2

Callao - América del Norte: 11.0 Callao - Europa: 13.8

Hacia Asia: 08 Hacia América del Norte: 20 Hacia Europa: 12

2200 TEU, barco con grúas propias

Total: 1131

Asia: 209

América del Norte: 607

Europa: 315

Total: casi equilibrado $=1.11$ Asia: superávit $=2.48$

América del Norte: déficit $=0.79$ Europa: superávit $=1.30$
Costa este: Argentina, Brasil, Uruguay

Total 25: Argentina 5, Brasil 19, Uruguay 1

Buenos Aires (Argentina) 25 Santos (Brasil) 27

Total: 556

Hacia Asia: 98

Hacia América del Norte: 196 Hacia Europa: 273

Todos servicios: 12500 Hacia Asia: 10906

Hacia América del Norte: 18121

Europa: 9302

Buenos Aires - Singapur: 25 días Buenos Aires - Hong Kong: 29 días Buenos Aires - Yokohama: 35 días Buenos Aires - Nueva York: 16 días Buenos Aires - Hamburgo: 19 días Santos - Singapur: 21 días Santos - Hong Kong: 25 días Santos - Yokohama: 31 días Santos - Nueva York: 14 días Santos - Hamburgo: 15 días

Santos - Asia: 9.6

Santos - América del Norte: 9.4 Santos - Europa: 9.3 Buenos Aires - Asia: 8.4 Buenos Aires - Am. del Norte: 9.7 Buenos Aires - Europa: 9.2

Hacia Asia: 14

Hacia América del Norte: 30 Hacia Europa: 23

3428 TEU, barco sin grúas, usado en servicio hacia Asia

Total: 2200

Asia: 349

América del Norte: 1051

Europa: 800

Total: casi equilibrado $=0.96$

Asia: superávit $=2.23$

América del Norte: Déficit $=0.68$

Europa: casi equilibrado $=1.07$

Fuente: Elaboraciones propias, basadas en American Shipper (2000); Datamar Consultores Asociados (2000), y World Sea Trade Service (1998).

a Los puertos de la costa norte de Sudamérica (Cayena, Colombia, Guyana, Surinam y Venezuela) no están considerados. TEU: Twenty foot equivalent unit, unidad de contenedor equivalente a un contenedor de veinte pies. San Antonio incluye servicios desde Valparaíso. Muchos servicios son el resultado de una cooperación entre varias empresas navieras.

b Buenaventura.

c Solamente servicios directos; éstos pueden implicar escalas en otros puertos, pero sin transbordo.

d Aproximación basada en los servicios ofrecidos en enero del 2000 y los contenedores movidos durante 1998. 
GRAFICO 2

Costa oeste y costa este sudamericanas: Servicios marítimos de línea según región de destino, enero del 2000

(Porcentajes y número de servicios)

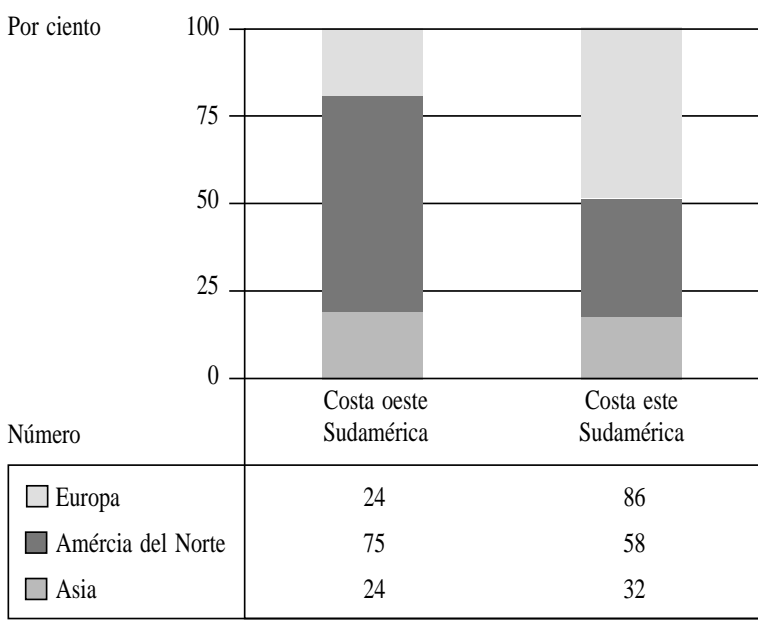

Fuente: Elaboración propia, basada en American Shipper (2000).

costa este de Sudamérica y la costa oeste de América del Norte. Sin embargo, hay que tener en cuenta que para llegar a cualquier destino dentro de los Estados Unidos y Canadá no hace falta entrar por una costa u otra, ya que allí las conexiones intermodales, a diferencia de Sudamérica, proveen servicios desde cualquier puerto de esos dos países.

En cuanto a los servicios hacia Asia, para la mayoría de los destinos conviene usar los servicios que salen desde Argentina, Brasil o Uruguay, siempre y cuando las conexiones intermodales terrestres dentro de Sudamérica lo permitan.

En resumen, los servicios ofrecidos en los puertos de ambas costas reflejan básicamente las necesidades del comercio nacional. Mayores volúmenes en la costa este resultan en más servicios, en barcos más grandes y en una mayor frecuencia. La mayor relevancia relativa de servicios hacia Europa desde la costa este, y hacia América del Norte desde la costa oeste, refleja básicamente las necesidades del comercio exterior con estas regiones (véase más atrás el gráfico 1).

\section{c) Servicios regulares desde la costa sudamericana del Pacífico}

Actualmente, no hay servicios regulares internacionales desde los puertos principales de la costa oeste sudamericana que hagan transbordo de contenedores dentro de Sudamérica. Hay servicios directos y
CUADRO 8

Costa sudamericana del Pacífico: Servicios regulares directos por puerto

\begin{tabular}{lccc}
\hline \multirow{2}{*}{ Puerto } & \multicolumn{3}{c}{ Número de servicios } \\
\cline { 2 - 4 } & Asia & Norteamérica & Europa \\
\hline Buenaventura (Colombia) & 3 & 8 & 2 \\
Guayaquil (Ecuador) & 3 & 10 & 3 \\
Callao (Perú) & 4 & 14 & 4 \\
Iquique (Chile) & 4 & 8 & 1 \\
Antofagasta (Chile) & 2 & 4 & 2 \\
Valparaíso y San Antonio (Chile) & 4 & 14 & 4 \\
Talcahuano y San Vicente (Chile) & 2 & 4 & 1
\end{tabular}

Fuente: Elaboración propia, basada en American Shipper (2000).

existe también la opción de servicios con transbordo en Centroamérica o Norteamérica.

Para servicios regulares que conectan la costa del Pacífico con Asia, hay servicios directos que incluyen los principales puertos de Chile, Perú, Ecuador y Colombia, y cruzan el Pacífico desde Buenaventura, Callao o San Antonio (por ejemplo, de las líneas navieras CSAV, Nedlloyd, NYK, P\&O Nedlloyd y Rickmers). También hay servicios indirectos que incluyen un transbordo, por ejemplo, en el puerto MIT de Panamá o en Los Angeles (de las líneas APL, CCNI, COSCO, Ecuadorian Line, Hapag Lloyd y Maersk).

Un análisis de los servicios regulares que cubren la costa del Pacífico sur indica que todas las principales líneas navieras incluyen a Callao y San Antonio. Algunos utilizan San Antonio en lugar de Valparaíso, pero no existe ningún servicio que incluya a Callao y no haga también escala en San Antonio o en Valparaíso. El cuadro 8 muestra el número de servicios regulares por puerto.

\section{d) El escenario futuro}

Las líneas marítimas tienden a establecer rutas principales este-oeste, con servicios de transbordo que conecten éstas con los servicios norte-sur. La tendencia hacia más servicios con transbordo también se refleja en las estadísticas que indican que el crecimiento del tráfico portuario es mayor que el de los movimientos marítimos: cada movimiento de un contenedor entre el país exportador y el importador constituye un solo movimiento marítimo, mientras que puede implicar dos, cuatro, o más movimientos portuarios, dependiendo del número de transbordos a lo largo del viaje.

El gráfico 3 ilustra un posible escenario futuro de servicios regulares de líneas navieras. Seguramente no se llegará al extremo de tener sólo servicios indirectos desde la costa occidental sudamericana, pero definiti- 


\section{GRAFICO 3}

\section{Mundo: Posible escenario futuro de servi- cios directos e indirectos ${ }^{a}$}

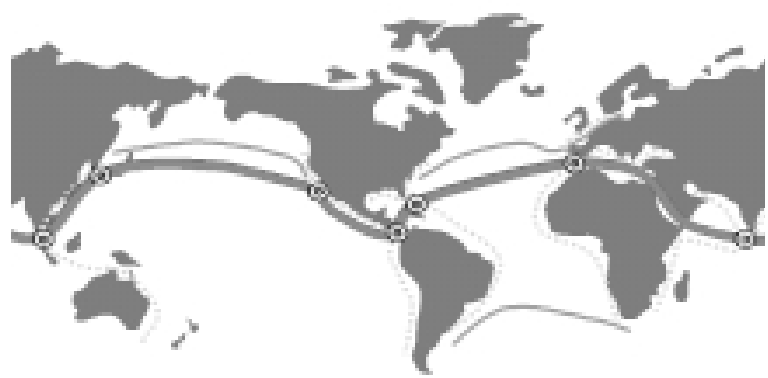

Fuente: Containerisation International (1999).

a La línea gruesa indica servicios este-oeste alrededor del mundo en barcos de hasta $15000 \mathrm{TEU}$, suponiendo una ampliación del Canal de Panamá. Alternativamente, podrían existir servicios de péndulo que tuviesen origen y destino final en ambas costas de Estados Unidos. Las tres líneas seguidas más cortas indican servicios directos entre Asia y América del Norte, América del Norte y Europa, y América del Sur y Sudáfrica. Las líneas interrumpidas indican servicios alimentadores que se conectan con el servicio principal este-oeste. vamente se observa una tendencia en ese sentido. Para varios servicios regulares en la costa del Pacífico sudamericano el escenario descrito en el gráfico ya es casi una realidad: los puertos pivotes principales son Long Beach en Estados Unidos, MIT en Panamá y Kingston en Jamaica.

\section{Distancias para servicios en barcos charter}

No todo el comercio se transporta en líneas marítimas regulares. Gran parte - sobre todo en el caso de graneles secos y líquidos - se transporta en barcos charter que se alquilan para viajes determinados y que no siguen rutas establecidas para cubrir un horario de puertos, sino que buscan básicamente la distancia más corta.

La comparación de distancias no debe considerar sólo la travesía del Pacífico, sino también la alternativa de pasar por el Cabo de Buena Esperanza en Sudáfrica. Tampoco hay que incluir únicamente los puertos asiáticos más orientales, sino también los puertos más grandes, que son Hong Kong y Singapur (cuadro 9).

CUADRO 9

\section{Distancias marítimas}

\begin{tabular}{|c|c|c|c|c|c|c|c|}
\hline & Panamá & Singapur & Hong Kong & Yokohama & Los Angeles & Nueva York & Hamburgo \\
\hline Los Angeles & 2912 & 7867 & 6380 & 4839 & 0 & $\begin{array}{r}4930 \\
\text { v. Panamá }\end{array}$ & $\begin{array}{r}8012 \\
\text { v. Panamá }\end{array}$ \\
\hline $\begin{array}{l}\text { Panamá } \\
\text { (Colón) }\end{array}$ & 0 & 10504 & 9194 & 7725 & 2956 & 1972 & 5005 \\
\hline Buenaventura & 395 & 10375 & 9317 & 7681 & 3047 & $\begin{array}{r}2369 \\
\text { v. Panamá }\end{array}$ & $\begin{array}{r}5440 \\
\text { v. Panamá }\end{array}$ \\
\hline Guayaquil & 892 & 10726 & 9505 & 7987 & 3228 & $\begin{array}{r}2872 \\
\text { v. Panamá }\end{array}$ & $\begin{array}{r}5947 \\
\text { v. Panamá }\end{array}$ \\
\hline Callao & 1387 & 10676 & 10018 & 8558 & 3654 & $\begin{array}{r}3367 \\
\text { v. Panamá }\end{array}$ & $\begin{array}{r}6442 \\
\text { v. Panamá }\end{array}$ \\
\hline Antofagasta & 2178 & 10524 & 10532 & 9154 & 4433 & $\begin{array}{r}4.158 \\
\text { v. Panamá }\end{array}$ & $\begin{array}{r}7233 \\
\text { v. Panamá }\end{array}$ \\
\hline $\begin{array}{l}\text { Valparaíso/ } \\
\text { S. Antonio }\end{array}$ & 2858 & 9945 & 10532 & 9280 & 4806 & $\begin{array}{r}4638 \\
\text { v. Panamá }\end{array}$ & $\begin{array}{r}7713 \\
\text { v. Panamá }\end{array}$ \\
\hline Recife & 3217 & $\begin{array}{r}8934 \\
\text { v. Sudáfrica }\end{array}$ & $\begin{array}{r}10220 \\
\text { v. Sudáfrica }\end{array}$ & $\begin{array}{r}10942 \\
\text { v. Panamá }\end{array}$ & $\begin{array}{r}6173 \\
\text { v. Panamá }\end{array}$ & 3698 & 4450 \\
\hline Río de Janeiro & 4289 & $\begin{array}{r}8863 \\
\text { v. Sudáfrica }\end{array}$ & $\begin{array}{r}10149 \\
\text { v. Sudáfrica }\end{array}$ & $\begin{array}{r}11517 \\
\text { v. Magallanes }\end{array}$ & $\begin{array}{r}7245 \\
\text { v. Panamá }\end{array}$ & 4780 & 5535 \\
\hline Santos & 4565 & $\begin{array}{r}9035 \\
\text { v. Sudáfrica }\end{array}$ & $\begin{array}{r}10321 \\
\text { v. Sudáfrica }\end{array}$ & $\begin{array}{r}11335 \\
\text { v. Magallanes }\end{array}$ & $\begin{array}{r}7521 \\
\text { v. Panamá }\end{array}$ & 4955 & 5710 \\
\hline Buenos Aires & 5390 & $\begin{array}{r}9301 \\
\text { v. Sudáfrica }\end{array}$ & $\begin{array}{r}10587 \\
\text { v. Sudáfrica }\end{array}$ & $\begin{array}{r}10647 \\
\text { v. Magallanes }\end{array}$ & $\begin{array}{r}7243 \\
\text { v. Magallanes }\end{array}$ & 5910 & 6665 \\
\hline
\end{tabular}

Fuente: Fairplay Ports Guide, 1998. 
Algunas comparaciones son quizás sorprendentes:

- Desde cualquier puerto brasileño o desde Buenos Aires se llega antes a Singapur que desde cualquier puerto de la costa oeste sudamericana.

- Río de Janeiro está a la misma distancia de Hong Kong que Antofagasta, que se encuentra en la misma latitud.

- Para llegar de Buenos Aires a Los Angeles es más corto pasar por el Estrecho de Magallanes que usar el Canal de Panamá.

- Valparaíso parece estar más cerca de Singapur que Callao. Sin embargo, esta distancia directa pasa muy cerca de la Antártica y probablemente no es viable para la mayoría de los viajes.

- Nueva York está más cerca de Callao y Valparaíso que Los Angeles. La distancia económica, sin embargo, es mayor que lo que indican las millas, ya que para llegar a Nueva York hay que pasar por el Canal de Panamá.

- Colombia, Ecuador, Perú e incluso Chile están más cercanos a Europa que a Asia.

- Hacer un transbordo en Los Angeles durante un servicio de transporte entre Asia y la costa oeste de Sudamérica prácticamente no aumenta la distancia total. Viajar de Guayaquil a Singapur vía Los Angeles implica un desvío de solamente $3.5 \%$. Viajar de Callao a Hong Kong vía Los Angeles implica un desvío de menos del $1 \%$. Viajar de Valparaíso a Yokohoma vía Los Angeles implica un desvío de menos del $4 \%$.

Vemos así que, en cuanto a distancias marítimas, la costa del Pacífico sudamericano no ofrece una ventaja comparativa para el comercio de Sudamérica con Asia. Pero sí tiene, comparada con la costa del Atlántico, una ventaja para el comercio con América del Norte.

\section{Reserva de carga}

Aunque ya no exista la reserva de carga tradicional que hasta los años ochenta obstaculizaba el comercio por vía marítima de toda la región, siguen vigentes varios acuerdos bilaterales que evitan que las empresas navieras internacionales sirvan al comercio intrarregional y al cabotaje nacional.

Por ejemplo, las líneas navieras internacionales que conectan a Chile con Europa, América del Norte y Asia hacen escala en los puertos principales de la costa del Pacífico sudamericano, como Callao, Guayaquil y Buenaventura. Sin embargo, varias de ellas no pueden transportar carga entre San Antonio (Chile) y
Guayaquil (Ecuador) o entre San Antonio y Buenaventura (Colombia). Por ejemplo, Mitsui OSK, en los anuncios de sus servicios en Chile, ni siquiera menciona las escalas de sus barcos en Guayaquil y Buenaventura porque si un cliente chileno quisiera usar los servicios de Mitsui OSK para dicha ruta eso le estaría prohibido.

Lo mismo sucede dentro de los países. En Chile, barcos que no usan la bandera chilena no pueden llevar carga de Valparaíso a Antofagasta o Iquique, aunque tengan espacio ocioso - y por lo general lo tienen. La oposición a una apertura del cabotaje proviene sobre todo de los sindicatos que representan a la mano de obra empleada por empresas navieras y también por empresas de transporte terrestre. Ambos grupos están conscientes del peligro de perder puestos de trabajo si el transporte marítimo nacional se abre a líneas que no usan la bandera nacional y que, por lo tanto, tampoco tienen que emplear personal a bordo nacional.

Esta reserva de carga también es un obstáculo para el desarrollo portuario, ya que cada contenedor que sale del puerto por vía terrestre en vez de marítima aumenta la congestión en el tráfico urbano y disminuye el número de movimientos portuarios.

En resumen, la concentración de carga en puertos pivotes se hace más difícil si las empresas navieras internacionales están excluidas de estos servicios y si además éstos se encarecen insistiendo en el uso de una bandera determinada.

\section{4. $\quad$ Fletes}

Los fletes marítimos fluctúan diariamente y dependen de muchos factores como el tipo de producto, los balances de comercio, la distancia, el uso de contenedores y el tamaño del contenedor usado, el valor de la mercancía, la productividad portuaria y las economías de escala. El cuadro 10 muestra los gastos registrados por aduanas en flete marítimo y seguros de las importaciones por vía marítima de cinco países sudamericanos. Las disparidades entre los países se explican en gran parte por los diferentes productos que importan. Por ejemplo, Brasil importa muchos cereales desde Argentina, lo que implica menores costos de transporte por tonelada que, por ejemplo, las importaciones de vehículos que hace Argentina desde Asia.

Un análisis econométrico más detallado que considera los diferentes productos, la distancia, el valor de la mercancía y los volúmenes, indica que dentro del mismo grupo de productos - por ejemplo, fertilizantes o vehículos - cada aumento de volumen de $1 \%$ 
CUADRO 10

Sudamérica (cinco países): Fletes y seguros de las importaciones por vía marítima y fluvial, 1998

\begin{tabular}{lcc}
\hline País & \multicolumn{2}{c}{ Diferencia entre valor cif y valor fob } \\
\cline { 2 - 3 } & \% del valor fob & Dólares por tonelada \\
\hline Argentina & 6.5 & 56 \\
Brasil & 6.2 & 27 \\
Chile & 8.4 & 47 \\
Perú & 9.2 & 40 \\
Uruguay & 8.3 & 51 \\
\hline
\end{tabular}

Fuente: CEPAL, 2000

significa una reducción de los costos de transporte por tonelada de 0.1 a $0.2 \%$, lo que se explica por el uso de barcos más grandes y equipos más especializados en los puertos. Dado que Brasil tiene mayores volúmenes de importación, era de esperar que también pagara menos por su transporte.

Cotizaciones de fletes obtenidas de empresas navieras confirman que, a inicios del 2000, los fletes por exportación de contenedores desde los países del Mercosur eran menores que desde Chile, Ecuador o Perú. El personal de venta de las diferentes empresas coincidía en la explicación de que en la costa este de Sudamérica hay mayor competencia, se usan barcos más grandes, y el costo por barco en cada puerto es menor si se puede distribuir entre un mayor número de contenedores. Según Sgut (1999) "el mercado de fletes al Lejano Oriente y a Australasia es un $30 \%$ más bajo desde la costa del Atlántico que desde la del Pacífico". Hay que subrayar, sin embargo, que el flete de cada transacción comercial depende de muchos factores y que las fluctuaciones en ambas costas no siempre son paralelas.
En enero del 2000 el flete terrestre entre Buenos Aires y Valparaíso era de 1650 dólares por contenedor de veinte pies. Según información oficiosa de tres empresas navieras y un agente de carga, ese mismo mes los fletes marítimos para carga FAK (Freight all Kind) desde Asia, América del Norte o Europa hacia puertos sudamericanos, oscilaban entre 1400 y 2000 dólares, siendo los valores hacia el Atlántico menores que hacia el Pacífico. Comparando el flete terrestre con el marítimo, cabe esperar que sea poca la carga proveniente de una capital en un lado de Sudamérica que salga del continente por un puerto del lado contrario.

La interdependencia de los fletes en diferentes mercados se nota si se examinan los que se aplican entre Asia y la costa oeste de Sudamérica. Según los datos expuestos más atrás en el cuadro 7 , existe un superávit de comercio en contenedores a favor de Sudamérica, de modo que cabría esperar que el flete de exportación fuese mayor que el de importación ya que en Sudamérica faltan contenedores vacíos. Sin embargo, el flete de importación desde Singapur en enero del 2000 era aproximadamente $40 \%$ mayor que el flete de exportación desde Sudamérica hacia Singapur. La razón es el fuerte desequilibrio en el comercio entre Estados Unidos y Asia, que causa un superávit de contenedores vacíos en la costa oeste de las Américas.

En resumen, los fletes en el comercio exterior por vía marítima de Sudamérica coinciden con lo esperado en vista de los volúmenes, balances y productos del intercambio de los países sudamericanos con otras regiones. Los fletes marítimos son mucho más bajos que los terrestres, y los fletes correspondientes a la costa del Atlántico en la actualidad son menores que los de la costa del Pacífico.

\section{V}

\section{Los puertos y el tráfico portuario}

\section{Economías de escala}

Los costos del tráfico portuario son más bajos si se puede usar la última tecnología y la mejor superestructura. Con costos fijos cada vez mayores y costos variables menores el aumento del volumen acarrea una reducción de los costos por contenedor. Esto atrae carga adicional, lo que a su vez hace bajar los costos unitarios. Es un círculo virtuoso.

Comparando las costas sudamericanas del Atlántico y del Pacífico, se observa que la primera tiene mayores posibilidades de conseguir economías de escala. A juzgar por las toneladas de carga movidas, incluido cabotaje (gráfico 4), los puertos de la costa 


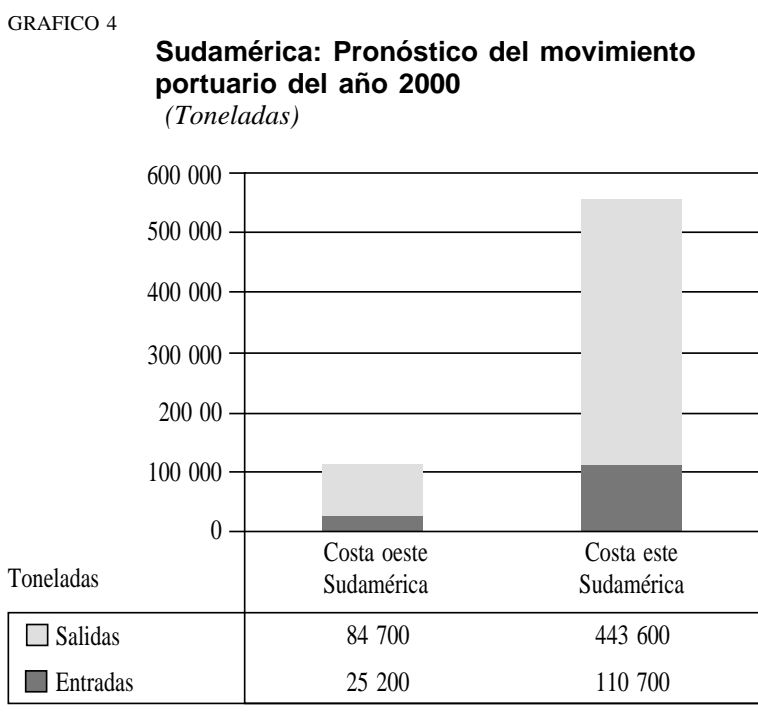

Fuente: UNCTAD, 1999.

CUADRO 11

Sudamérica: 25 puertos principales en el Atlántico y en el Pacífico sur, $1998^{a}$ (Millones de toneladas métricas)

\begin{tabular}{lc}
\hline Puerto & Volumen \\
\hline Tubarão (Brasil) & 69.6 \\
Itaqui (Brasil) & 50.3 \\
São Sebastião (Brasil) & 42.4 \\
Santos (Brasil) & 24.9 \\
Aratu (Brasil) & 19.1 \\
Paranagua (Brasil) & 19.1 \\
Buenos Aires (Argentina) & 18.8 \\
San Lorenzo (Argentina) & 18.6 \\
Angra dos Reis (Brasil) & 18.4 \\
Praia Mole (Brasil) & 15.4 \\
Bahía Blanca (Argentina) & 14.8 \\
Balao (Ecuador) & 14.1 \\
Río de Janeiro (Brasil) & 11.3 \\
Belem (Brasil) & 12.6 \\
Ponta Ubu (Brasil) & 11.7 \\
São Francisco (Brasil) & 11.2 \\
Río Grande (Brasil) & 11.5 \\
Rosario (Argentina) & 11.4 \\
Callao (Perú) & 10.2 \\
Caleta Olivia (Argentina) & 8.6 \\
Buenaventura (Colombia) & 7.3 \\
San Antonio (Chile) & 7.4 \\
Caleta Cord. (Argentina) & 7.3 \\
San Vicente (Chile) & 7.0 \\
Quequén (Argentina) & 6.5 \\
\hline
\end{tabular}

Fuente: CEPAL, 2000.

a No se incluyen puertos de Colombia y Venezuela de la costa norte de Sudamérica. este transportan cinco veces más carga que los del lado oeste.

El puerto con más volumen de tráfico en Sudamérica es Tubarão (Brasil), donde se traslada sobre todo mineral de hierro, y el puerto con más volumen de tráfico en la costa del Pacífico es Balao (Ecuador), que atiende sobre todo a petroleros. De los 25 puertos con más volumen de tráfico en ambas costas 20 son del Atlántico y cinco del Pacífico (cuadro 11).

En resumen, para la carga a granel líquido y sólido, los puertos del Atlántico cuentan con una ventaja comparativa porque mueven grandes volúmenes de carga del propio hinterland, y los costos unitarios tienden a disminuir como consecuencia de economías de escala.

\section{El peligro de monopolios privados}

En los países sudamericanos los puertos públicos se han estado privatizando en los últimos años; muchos puertos especializados han sido privados desde su construcción, y se están construyendo nuevos puertos privados.

Esta tendencia hacia una mayor participación del sector privado crea cierto temor de que surjan monopolios privados. Uno de los principales desafíos relacionados con la privatización es el de seguir de cerca los procesos y evitar abusos monopolísticos del sector privado después de que el Estado deja de operar los puertos. Pero si no se privatizasen los puertos, igualmente existiría el peligro de monopolios públicos.

Es más difícil evitar monopolios en los puertos de la costa del Pacífico que en los de la costa del Atlántico. Desde muchas ciudades de Argentina y Brasil los importadores y exportadores tienen fácil acceso a varios puertos, mientras que por el lado del Pacífico suele darse que haya acceso a un solo puerto claramente dominante (por ejemplo, Buenaventura, Guayaquil o Callao). La competencia interportuaria es mayor entre los puertos de Argentina, Brasil y Uruguay; allí los exportadores e importadores tienen acceso a ferrocarriles, autopistas e incluso transporte fluvial que les da mayores opciones de elegir entre varios puertos. En Colombia, la competencia interportuaria es menos fuerte en el lado del Pacífico, donde domina Buenaventura, que en el lado caribeño, donde Cartagena, Barranquilla y varios puertos menores están compitiendo fuertemente por carga local y por carga de transbordo.

En Chile la situación no es tan difícil como en los otros tres países de la costa oeste, ya que existe una 
fuerte competencia entre San Antonio y Valparaíso. También hay competencia entre los puertos públicos de la antigua EMPORCHI (Empresa Portuaria de Chile, que se disolvió en 1999) y los puertos netamente privados (por ejemplo, en la región de Concepción), y entre puertos actuales y puertos que se están construyendo (por ejemplo, entre Antofagasta y Mejillones).

La necesidad de regular los puertos después de la privatización hace más difícil que éstos se conviertan en puertos pivotes. Los principales centros de transbordo en América Latina y el Caribe - MIT en Panamá, Kingston en Jamaica y Free Port en Bahamas - tienen tarifas confidenciales con sus clientes, lo que dificulta la tarea de control de los reguladores estatales.

$\mathrm{Si}$ se divide un puerto en varios terminales que compiten entre ellos, se crea competencia intraportuaria y se evitan así monopolios privados. Por otra parte, la división de un puerto como Callao, que maneja volúmenes relativamente bajos, dejaría muy poco movimiento marítimo para cada operador, lo que podría desincentivar mayores inversiones.

Las tarifas portuarias para la carga local y la carga de transbordo son diferentes. Para transbordo se cobra mucho menos que para la carga que sale del puerto por vía terrestre. Eso en parte refleja menores costos y también una mayor elasticidad de la demanda de servicios de transbordo.

En resumen, la libertad de fijar tarifas portuarias adaptadas a las necesidades del mercado es mucho más importante — de hecho imprescindible — para centros de transbordo que para puertos dedicados solamente a atender carga local. Tal libertad es más difícil, aunque no imposible, de otorgar en puertos públicos privatizados si el Estado teme abusos monopolísticos, como

\section{VI}

\section{El hinterland}

\section{El impacto de los Andes}

Sobre todo en Chile y Perú, pero parcialmente también en Ecuador y Colombia, la cordillera de los Andes obstaculiza seriamente las posibilidades de atraer carga de los países sudamericanos vecinos. Transportar carga a larga distancia por vía terrestre en camión - los ferrocarriles son poco relevantes en el comercio internacional de Sudamérica-, subiendo y bajando sucede en los principales puertos de la costa del Pacífico en Colombia, Ecuador y Perú.

\section{Aspectos físicos y geográficos}

Por la forma de la plataforma tectónica de Sudamérica y su movimiento relativo hacia el oeste, la costa del Pacífico tiene una fuerte inclinación y muy pocas bahías. Construir un rompeolas en ella cuesta mucho más que en otras costas. Eso también limita el potencial crecimiento de muchos puertos para convertirse en puertos pivotes. Una de las excepciones a esta restricción parece ser el puerto proyectado en Mejillones, en el norte de Chile.

Varios de los principales puertos de la costa también ven su futuro crecimiento restringido por su ubicación dentro de ciudades. Una de las razones del mayor crecimiento de San Antonio, comparado con su principal competidor Valparaíso, es su mejor conexión terrestre con Santiago y mayor espacio para expansión.

Finalmente, en toda la costa del Pacífico el peligro de terremotos y maremotos puede limitar el crecimiento portuario. Antofagasta y San Antonio, por ejemplo, sufrieron elevados daños en las últimas décadas. El costo de construcción de muelles, rompeolas y edificios en zonas de actividad sísmica es mayor que en otras zonas. Además, los costos de capital para los inversionistas siempre son más altos si se les agrega una prima para cubrir el riesgo de maremotos.

Vemos así que la tectónica, la congestión urbana y la falta de espacio para la expansión son factores limitantes para las posibilidades de muchos puertos de convertirse en puertos pivotes en el oeste de Sudamérica.

pasos cordilleranos a 3000 o 4000 metros de altura, solamente valdría la pena si al llegar al Pacífico se compensaran los costos de este transporte terrestre con otros ahorros.

No siempre los proponentes de nuevos proyectos portuarios parecen tener eso en cuenta, como se desprende por ejemplo de las expectativas que se han expresado en torno al hinterland de Mejillones (gráfico 5). 
GRAFICO 5

Chile: Expectativas cifradas en el hinterland de un puerto pivote en Mejillones

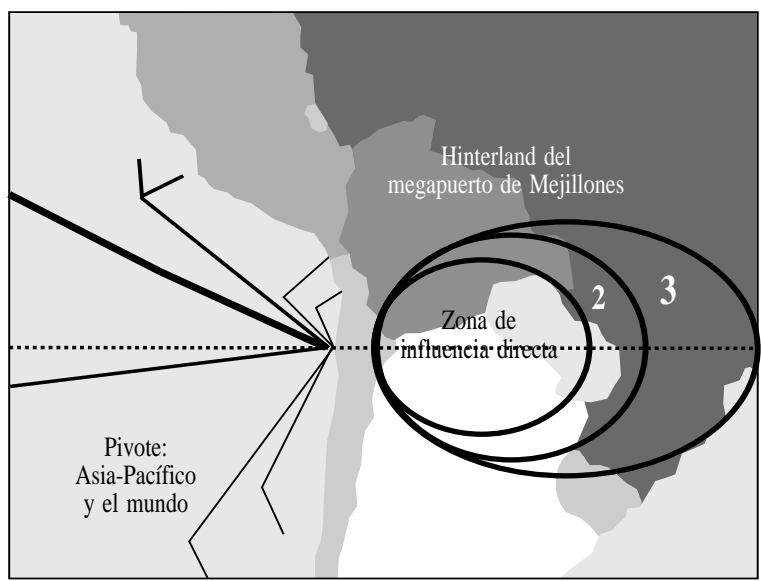

Zona de influencia directa: claramente elige el megapuerto de Mejillones.

Zona 2: para ella tiene ventaja el megapuerto de Mejillones.

Zona 3: plantea un desafío al megapuerto de Mejillones

Fuente: Schellmann, 1996.

En un breve estudio sobre potenciales privatizaciones portuarias en América Latina (Hoffmann, 1997) se estimó que el impacto de los Andes sobre el comercio entre Chile y Argentina equivale al de una distancia de unos $4700 \mathrm{~km}$. Es decir, aunque Chile y Argentina sean vecinos, lo que en la mayoría de los países del mundo significa mayor comercio bilateral, estos dos países tienen tanto comercio bilateral como si fuesen países separados por varios miles de kilómetros. Esto no quiere decir que cruzar los Andes en camión sea tan caro como viajar todos esos kilómetros, sino que el impacto del cierre de túneles y pasos en invierno, la incertidumbre respecto a cuando se cierran, el número limitado de pases, la necesidad de ajustar motores para la altura y el gasto adicional de energía, tienen en conjunto un efecto negativo sobre el comercio que equivale al de una gran distancia por terreno llano.

Evidentemente, las mejoras en la infraestructura de transporte terrestre reducen el impacto negativo de los Andes. En la actualidad tampoco se llega al extremo de que ninguna carga desde países vecinos pase por puertos de Colombia, Ecuador, Perú o Chile. Fruta del oeste de Argentina con destino a Estados Unidos ya pasa por Valparaíso y San Antonio. En 1999 el 1.7\% del volumen de carga de San Antonio tenía su origen o destino en Argentina, y el $0.6 \%$ en otros países sud- americanos. Los minerales del norte de Argentina y de Bolivia pueden pasar por Antofagasta o Mejillones. Mucho comercio boliviano ya pasa por Arica. La Zona Franca de Iquique se ha especializado exitosamente en importaciones desde Asia y Estados Unidos para destinos finales en Bolivia y los países del Mercosur. También varios otros puertos chilenos y peruanos están moviendo carga para Bolivia e incluso Paraguay. Un futuro crecimiento de la producción minera en el norte de Argentina y en el oeste de Bolivia puede desembocar en mayores volúmenes de carga para los puertos del norte de Chile y del sur de Perú.

Uno de los obstáculos que persiste entre varios países de la Comunidad Andina es la limitación de servicios de transporte terrestre a transportistas nacionales, que obliga a hacer transbordos entre camiones en la frontera.

El aumento de los flujos de comercio de países vecinos que pasan por puertos de Perú o Chile depende sobre todo de mejoras en la infraestructura terrestre. Sin embargo, al proyectar el impacto de tales mejoras hay que tener en cuenta que las conexiones terrestres en Argentina y Brasil también se están mejorando. En el Mercosur se han privatizado los ferrocarriles, se está dragando la hidrovía del Paraná, y en general la infraestructura vial se está mejorando con inversiones privadas y públicas. El flete terrestre por ferrocarril para un contenedor entre las ciudades argentinas de Mendoza y Buenos Aires costaba 500 dólares a finales del 1999, mientras que el flete por camión entre Mendoza y Valparaíso (Cámara Marítima de Chile A.G., 1999) oscilaba entre 500 y 800 dólares según el peso. Es decir, aunque Mendoza está tres veces más lejos de Buenos Aires que de Valparaíso, el transporte desde esa ciudad hacia Buenos Aires es menos costoso.

Sgut (1999) opina que los proyectos de corredores bioceánicos "arriban a los despachos de los ministros de transporte y luego de los mismos jefes de Estado, quienes por razones políticas no están en condiciones de condenar ninguna iniciativa, aunque ésta no sea económicamente factible".

En resumen, la región sudamericana está geográficamente dividida por la segunda cordillera más alta del mundo. Esta cordillera implica una desventaja para los puertos del oeste sudamericano que quieran atraer carga de países vecinos.

\section{El crecimiento económico y la carga local}

Los puertos sudamericanos del Pacífico tienen potencial de crecimiento, basado sobre todo en la carga 
nacional y en el hinterland cercano. Que esta carga local llegue a su destino por servicios directos o con un transbordo en un país extranjero tiene poca importancia para el negocio portuario propio o para el comercio exterior.

A largo plazo se espera que el crecimiento económico de América Latina esté por encima del promedio mundial. A más corto plazo las perspectivas, sobre todo para Ecuador y Colombia, no parecen tan promisorias. En cualquier caso, todos los países necesitan puertos eficientes - para su propio comercio.

Los operadores portuarios que son potenciales inversionistas en los puertos que se están concesio- nando a lo largo de la costa confirman también su interés en la carga local, a veces llamada "cautiva", con la cual esperan hacer negocios interesantes. El transbordo de contenedores, en cambio, les parece un negocio inseguro y volátil. Tampoco pueden basar sus inversiones millonarias en expectativas inciertas de carga a granel proveniente de países vecinos, que pueden o no materializarse una vez que se hayan realizado mejoras en las conexiones de transporte terrestre.

En la actualidad, el tráfico portuario en la costa oeste de Sudamérica se genera en gran parte gracias al comercio nacional de cada país, y probablemente seguirá siendo así en el futuro.

\section{VII}

\section{Concentración de carga sí, ¿pero dónde?}

\section{Por vía terrestre o por vía marítima}

La carga para un puerto pivote puede provenir del hinterland — por vía terrestre — o llegar por vía marítima para un transbordo en el puerto. Se ha mostrado que las posibilidades de concentrar carga por vía terrestre en la costa oeste de Sudamérica son limitadas. En una costa muy larga, con ciudades cercanas al mar y un hinterland restringido por los Andes, es difícil seguir el ejemplo de Rotterdam, Los Angeles y Hong Kong, o incluso de São Paulo o Buenos Aires en la costa este sudamericana.

En la actualidad, el principal corredor este-oeste en Sudamérica es el que conecta Valparaíso, Santiago, Mendoza y Buenos Aires. Se fundamenta en el comercio bilateral entre Argentina y Chile, y tiene que cubrir una menor distancia que otros corredores más al norte. Para las zonas de producción agrícola y minera en el oeste de Argentina puede ser ventajoso el uso de puertos chilenos, sobre todo en su comercio con Estados Unidos. Sin embargo, no se prevén razones por las cuales estos flujos de tránsito por puertos chilenos debieran modificarse mucho en comparación con los existentes en la actualidad.

Las limitaciones a la concentración de carga por vía terrestre no se aplican a la concentración de carga por vía marítima en centros de transbordo. Las tendencias que se observan en el transporte marítimo hacen que el porcentaje de contenedores que se transbordan por lo menos una vez durante su viaje esté aumentando. Cabe preguntarse si este transbordo se efectúa a lo largo de la propia costa de Sudamérica, o fuera de la región.

En suma, es poco probable que en puertos del oeste sudamericano se concentren grandes volúmenes de carga por vía terrestre. Es posible que la carga en contenedores que sale por vía marítima pase por centros de transbordo, aunque estos no necesariamente estén ubicados en Sudamérica.

\section{Fuera de Sudamérica}

En un estudio que se contrató para el proyecto del puerto de Mejillones en el norte de Chile, se estimó un potencial de ocho millones de toneladas de carga en contenedores para un servicio de transbordo en este pueblo cercano a Antofagasta. Aunque la cifra fuese factible, el lugar no parece serlo. Por el momento, no parece viable un centro de transbordo más grande en la costa occidental sudamericana.

Para viajes a Europa y la costa este de América del Norte, un transbordo en Panamá, Jamaica, o Freeport (Bahamas), casi no significa desvío de la ruta principal norte-sur. Estos puertos cuentan con mayores volúmenes de carga propios, y están ubicados en cruces de varias rutas este-oeste y norte-sur.

Para viajes a Asia, un transbordo en Panamá o Los Angeles implica un desvío de entre cero y cinco por 
ciento (véase más atrás el cuadro 9). Los Angeles/Long Beach es uno de los tres principales puertos de contenedores del mundo. De allí salen diariamente los barcos más grandes hacia Asia, y los barcos provenientes de América del Sur pueden a la vez dejar carga con origen o destino en América del Norte.

Entre los pedidos mundiales registrados por los productores de grúas gantry casi no hay encargos de los puertos de Sudamérica occidental. A inicios de 1999, América Latina y el Caribe en su conjunto originó el 12\% de los pedidos mundiales (un total de 161). Este porcentaje es mayor que el que le correspondería por su tráfico portuario en contenedores y refleja las modernizaciones que se estaban efectuando ese año en Centroamérica, el Caribe y el Mercosur. En la costa del Pacífico, solamente Buenaventura tenía pedidos de grúas gantry pendientes. Con inversiones y expansiones en dragados, grúas y espacio para contenedores en los principales puertos a lo largo de la costa probablemente se podrán atraer servicios regulares con barcos más grandes y, algún día, que no necesiten grúas propias. Con eso se haría más económico el transporte del comercio exterior de todos los países sudamericanos que bordean el Pacífico, se haga o no después un transbordo de esta carga en países fuera de la región.

MIT, en el lado caribeño de Panamá, es uno de los puertos donde más ha crecido el tráfico de transbordo en los últimos años, y se espera que seguirá creciendo. Igualmente, en la costa del Pacífico se espera un aumento del volumen de este tráfico en Balboa, donde recientemente se iniciaron operaciones para atraerlo y hay además otros proyectos para construir puertos nuevos que competirían con Balboa en el lado del Pacífico. También en Panamá se acaba de entregar en concesión el ferrocarril que conecta puertos en ambas costas del país, haciendo posible transbordos entre dos océanos. Todos estos avances, combinados con la gran ventaja de contar con el Canal de Panamá, sugieren que el papel de puertos panameños como centros de transbordo seguirá teniendo creciente importancia. Ellos tienen mejor ubicación que los puertos sudamericanos para conectar mercados regionales como Centroamérica, la subregión del Caribe y la costa oeste de Sudamérica, con las principales rutas este-oeste.

En resumen, en vista de las tendencias observadas en el transporte marítimo, y un escenario futuro como el que muestra el gráfico 3 , es de esperar que aumente la proporción del movimiento marítimo en contenedores con uno o más transbordos. Sin embargo, estos transbordos se realizarán en puertos con mayor volumen de tráfico y ubicados más cercanos a las rutas principales del comercio este-oeste, como Los Angeles, MIT, Kingston (Jamaica) o Freeport (Bahamas).

\section{En la costa occidental de Sudamérica}

No se puede excluir totalmente la viabilidad de transbordos en algunos puertos del oeste sudamericano. Como se vio en el cuadro 6, por ejemplo, el $6 \%$ del movimiento de contenedores en Callao ya es de transbordo.

Si se liberalizan los servicios de cabotaje y si se termina la reserva de carga entre varios países a lo largo de la costa del Pacífico sudamericano, las mismas líneas internacionales podrían más fácilmente establecer sus propios servicios alimentadores. Sin embargo, la misma liberalización también haría más eficientes los servicios directos, porque una línea podría aprovechar mejor su capacidad ociosa, recolectando carga a lo largo de la costa mientras está llenando su barco.

Las inversiones previstas para los próximos años en los puertos de Colombia, Ecuador, Perú y Chile harán más factible el uso de barcos de contenedores más grandes, incluso posiblemente sin grúas propias. En la actualidad, sin embargo, la principal empresa naviera chilena, CSAV, tiene pendientes pedidos de barcos de 3100 TEU con grúas propias para contenedores, lo que indica que no considera suficientes las grúas previstas en los puertos. Los barcos de este tipo sirven para trayectos largos, con volúmenes de carga relativamente altos. Los puertos pivotes en la misma costa oeste de Sudamérica requerirían barcos menores con grúas propias, para después pasar a servir barcos más grandes, con menores costos por TEU y menos tiempo en los puertos, lo que implicaría necesariamente el uso de barcos sin grúas propias y la realización de los transbordos con las grúas del puerto.

Si algún día hubiese mayor concentración de carga en contenedores en la costa oeste sudamericana, Callao sería probablemente el puerto más apto para convertirse en un centro de transbordo. Aunque sea poco probable, las empresas navieras podrían tener el incentivo de dejar de ir medio llenas hasta Valparaíso y San Antonio. En caso de que el crecimiento económico exhiba en Perú un ritmo igual o más alto que en Chile, la mayor población de Perú haría posible, aunque no probable, que a largo plazo Callao también tuviera más volumen de tráfico portuario que Valparaíso y San Antonio juntos. Entonces, por economías de escala, las tarifas portuarias podrían ser más bajas y los importadores y exportadores tendrían a su dis- 
posición más frecuencias en servicios regulares. Como Callao está más al norte, el desvío de la ruta principal este-oeste sería menor.

En resumen, no se puede excluir totalmente la viabilidad de actividades de transbordo en puertos del oeste sudamericano. El puerto con mayores posibili- dades de llevarlas a cabo podría ser Callao. Sin embargo, San Antonio y Valparaíso tienen mayores posibilidades de atraer carga de un hinterland más amplio, incluido el de Argentina, y así seguir justificando servicios directos que no pasen por un centro de transbordo en Perú.

\section{VIII}

\section{Resumen y conclusiones}

Las decisiones de elegir un modo de transporte u otro, pasar por un puerto u otro, o contratar servicios con o sin transbordo son principalmente decisiones empresariales. Sin embargo, el sector público tiene que preocuparse de la ubicación de los puertos pivotes porque éstos requieren inversiones privadas y públicas, y es el sector público el que define las condiciones para la participación del sector privado en tales puertos.

El comercio exterior de un país está estrechamente vinculado a su ubicación geográfica, los servicios de transporte que cubren las distancias hasta los mercados y los puertos por los cuales pasa este comercio. Surge así "una interesante veta de asociación público privada, pues el sector privado debería encargarse de la gestión y aportar los recursos para financiar las inversiones necesarias, el Estado por su parte debe establecer un marco legal abierto a la competencia, transparente, y por otra parte debiera a través de un enfoque de largo plazo, vincular armónicamente al puerto con su entorno y con su área de influencia" (Lagos, 1997). Es entonces crucial analizar a fondo qué flujos de comercio requieren qué tipo de servicios de transporte, y cuál es el área de influencia actual y potencial de los puertos nacionales.

En todos los países de la costa sudamericana del Pacífico existen expectativas de puertos pivotes. Se espera poder concentrar carga por vía terrestre y por vía marítima, proveniente del propio país y de países vecinos. Estas expectativas han llevado a amplios programas de inversión pública en infraestructura portuaria y de transporte terrestre, y también han influido directamente en las condiciones establecidas para las privatizaciones portuarias.

La principal conclusión del presente análisis es que el potencial de puertos pivotes en la costa del Pacífico sudamericano es muy limitado. Para llegar a esta conclusión, se ha analizado el comercio de los países sudamericanos; se ha examinado la situación de puertos pivotes existentes en otras regiones del mundo; se han analizado los servicios de líneas regulares de transporte marítimo, las distancias marítimas y los fletes, y, finalmente, se han estudiado los volúmenes de tráfico portuario y las posibilidades de atraer carga de un hinterland más amplio. Los resultados de estos análisis son los siguientes:

i) Sudamérica es, después de Australia, la región con menos tráfico de transbordo. En la actualidad, el movimiento total de contenedores y el porcentaje del tráfico de transbordo dentro de este total son más bajos que en otras regiones. Sudamérica tiene una participación de sólo $0.5 \%$ del tráfico portuario de transbordo del mundo.

ii) Los fundamentos para un puerto pivote son su ubicación y el volumen de carga de su hinterland. Para poder convertirse en pivote, un puerto tiene que contar con amplias conexiones de transporte terrestre, estar ubicado en un lugar donde se conectan o cruzan rutas marítimas, o contar con altos volúmenes de carga que se generan en el entorno cercano del puerto. Ninguna de estas condiciones se da en el oeste de Sudamérica en la misma medida en que se da en puertos pivotes ya existentes en el mundo.

iii) En los países sudamericanos, los servicios regulares de transporte marítimo reflejan sobre todo las necesidades del comercio nacional. Por los mayores volúmenes de comercio en los puertos de la costa sudamericana del Atlántico, allí funcionan más servicios, con barcos más grandes y una mayor frecuencia que en los puertos de la costa del Pacífico. La mayor relevancia relativa de servicios hacia Europa desde la costa oriental, y hacia América del Norte desde la costa occidental, corresponde al comercio exterior con estas regiones.

iv) Los servicios marítimos desde Argentina, Brasil y Uruguay tienen ventajas sobre los servicios que salen de puertos del oeste de Sudamérica. Los países 
en la costa este de Sudamérica cuentan con dos veces más puertos, con un $56 \%$ más de servicios regulares que salen con mayor frecuencia y usan barcos más grandes, y cada servicio regular mueve un $35 \%$ más de contenedores. Los puertos de la costa del Atlántico mueven cinco veces más carga que los del Pacífico, y los fletes marítimos son más bajos. Estas ventajas son el resultado de los mayores volúmenes de comercio de los países del Mercosur y de ninguna manera se deberían interpretar como una crítica a los puertos o a la política portuaria y marítima de algún país sudamericano. De todas formas, estas diferencias implican que un exportador que tiene igual acceso a puertos en ambas costas encontrará varias ventajas si opta por un puerto del oriente.

v) La ubicación geográfica da una ventaja a los países del Pacífico sobre los del Atlántico en el comercio con América del Norte. Esto se debe a las distancias marítimas y también a que los servicios que conectan la costa sudamericana del Pacífico con Europa o Asia en gran parte pasan automáticamente por puertos norteamericanos. Un desvío por Los Angeles durante un viaje desde Chile, Colombia, Ecuador o Perú hacia Japón, Hong Kong o Singapur implica solamente un aumento de $1 \%$ a $5 \%$ de la distancia recorrida.

vi) La ubicación geográfica pone en desventaja a los países del Pacífico respecto al comercio con Europa. Las distancias desde puertos de la misma latitud en el este de Sudamérica son mucho menores y los barcos no tienen que pasar por el Canal de Panamá.

vii) La ubicación geográfica no da una ventaja a los países del Pacífico respecto al comercio con Asia. Yokohama (Japón) está más cerca de los países del Pacífico, Hong Kong está a la misma distancia de ambas costas sudamericanas, y Singapur está más cerca de Argentina, Brasil y Uruguay. Los servicios marítimos desde Santos o Buenos Aires hacia Asia pasan por Sudáfrica y Sri Lanka. Los servicios que salen de la costa oeste tienen la ventaja de poder conectarse en Los Angeles con servicios que conectan América del Norte y Asia, lo que les permite aprovechar los mayores barcos y frecuencias en esta ruta. En otras palabras, la única ventaja de los puertos de Chile, Ecuador y Perú en el comercio con Asia es justamente la posibilidad de conectarse con un centro de transbordo fuera de Sudamérica.

viii) El hinterland de los puertos del Pacífico está restringido por la cordillera de los Andes. El impacto negativo de los Andes sobre el comercio bilateral equivale a una distancia de varios miles de kilómetros de terreno llano. Transportar un contenedor desde Men- doza en el oeste de Argentina a Buenos Aires cuesta menos que transportarlo en camión a San Antonio (Chile) a pesar de que Buenos Aires está tres veces más lejos. En la actualidad los principales puertos registran porcentajes muy bajos de tráfico portuario de tránsito, y no se prevén mayores modificaciones de estos flujos de comercio.

ix) No habrá puertos pivotes en el oeste de Sudamérica. Aunque existiera la infraestructura adecuada de transporte terrestre, por el lado marítimo no hay suficientes razones para justificar una mayor concentración de carga por vía terrestre en puertos del Pacífico. Aunque esté aumentando el uso de contenedores y el porcentaje de movimientos de transbordo, los centros de transbordo para la carga de los países sudamericanos del Pacífico se encuentran fuera de la región: son puertos en las Bahamas, los Estados Unidos, Jamaica y Panamá.

Estas conclusiones ciertamente parecen pesimistas y pueden ser una decepción para quienes creen o creían en nuevas posibilidades de generar ingresos y empleos con la exportación de servicios portuarios a países vecinos. Sin embargo, en ningún caso se sugiere aquí no invertir en infraestructura de transporte o no modernizar y privatizar los puertos. Al contrario, las desventajas descritas en este artículo deberían ser un incentivo para acrecentar los esfuerzos por mejorar los servicios de transporte.

La intención de ofrecer servicios de transporte al comercio de los países vecinos ya es el resultado de un cambio de actitud muy positivo. Hasta hace pocos años se quería impedir que productos de otros países ganasen competitividad gracias a los puertos nacionales. Sin embargo, no se pueden forzar decisiones de empresas navieras u otros transportistas de concentrar carga en un lugar u otro. Se puede y debe reducir a un mínimo los obstáculos físicos y administrativos para que el transportista encuentre la solución más económica para su cliente. Mejoras en la infraestructura de transporte terrestre, la liberalización del cabotaje terrestre y marítimo, y la reducción de demoras en los pasos fronterizos beneficiarían directamente a los que quieren importar o exportar hacia otras regiones.

Tales avances también beneficiarían al comercio entre los países sudamericanos. Más de la mitad del volumen (en toneladas) de las importaciones de los países sudamericanos proviene de América Latina y el Caribe (CEPAL, 2000). Además, en los últimos años este comercio intrarregional ha crecido a una tasa mayor que el comercio interregional. Las inversiones en corredores bioceánicos dedicados a conectar los países 
con puertos pivotes que concentran la carga del comercio intercontinental parecen ser menos prometedoras que inversiones en corredores de comercio intrarregional que conectan los principales centros económicos de la región entre ellos.

En el pasado, los países competían con su comercio exterior y trataban de evitar que los países vecinos se beneficiasen de los puertos nacionales. Hoy en día, los puertos tratan de competir por el comercio de los países vecinos. Esta competencia es de por sí positi- va. Sin embargo, en muchos casos se ha elevado a un nivel político que ha convertido una simple competencia interportuaria en una pugna internacional entre hipotéticos futuros puertos pivotes. En vista de las bajas probabilidades de que el establecimiento de puertos pivotes sea exitoso, quizás convenga más buscar una mayor coordinación regional de políticas de transporte y de inversiones en infraestructura para fomentar la integración entre los países sudamericanos del Atlántico y del Pacífico.

\section{Bibliografía}

American Shipper (2000): 3 de enero www.compairdata.com

Camae (1999): Guayaquil, Ecuador, octubre.

Cámara Marítima de Chile A.G. (1999): 24 de octubre camport@entelchile.net

Cargo Systems (1999): noviembre www.cargosystems.net

CEPAL (Comisión Económica para América Latina y el Caribe) (1999): Perfil marítimo, Santiago de Chile, diciembre. (2000): Perfil marítimo, Santiago de Chile, enero http:// www.eclac.cl/espanol/investigacion/transporte/perfil/ index.htm

Comisión de Promoción de Concesiones Privadas (1998): Promcepri: Concessions of the Peruvian Sea Cargo Terminals, Lima, junio.

Containerisation International (1999): Londres, Informa Group, diciembre.

Datamar Consultores Asociados (2000): 4 de enero lorimer@ amcham.com.br

Drewry Shipping Consultants (1996): Post-Panamax Containerships, Londres.

(1999): Container Market Outlook, Londres.

El Diario (1999): Santiago de Chile, 2 de noviembre.

El Mercurio (1998): Santiago de Chile, 30 de mayo.

ENAPU (Empresa Nacional de Puertos) (sin fecha): Puertos del Perú, Lima.

Estrategia (1998): Santiago de Chile, 17 de junio.

Fairplay Ports Guide (1998): Londres, Fairplay Publications.

Gallup, J. y J. Sachs (1999): Geography and Economic Development, CAER II discussion paper, $\mathrm{N}^{\circ} 39$, Cambridge, Massachusetts, Harvard Institute for International Development, marzo.
Hoffmann, J. (1997): An overview of Latin American ports, en Ministerio de Obras Públicas, Seminario. Avances en la tecnología portuaria y marítima mundial y su relevancia en Chile, Santiago de Chile.

(1999): Concentración en los servicios de líneas regulares: causas del proceso y sus efectos sobre el funcionamiento de los puertos y de los servicios de transporte marítimo de las regiones en desarrollo, Santiago de Chile, CEPAL.

Lagos, R. (1997): Corredores bioceánicos, Santiago de Chile, agosto. Lloyds List (1999): Londres, 28 de abril.

Radelet, S. y J. Sachs (1998): Shipping costs, manufactured exports, and economic growth (trabajo presentado a la Annual Meeting of the American Economic Association), Nashville, Tennessee, American Economic Association.

Schellmann, M. (1996): Megaport of Mejillones, Preliminary working paper, Antofagasta, Chile, Gobierno Regional de Antofagasta, diciembre.

Sgut, M. (1999): Corredores bioceánicos, Buenos Aires, mimeo, diciembre martin.sgut@attglobal.net

Shednet News (1999): 16 de enero www.shednet.com

UNCTAD (Conferencia de las Naciones Unidas sobre Comercio y Desarrollo) (1999): Review of Maritime Transport 1999, Ginebra.

World Sea Trade Service (1998): WSTS Review, vol.1, Lexington, Massachusetts, The McGraw-Hill Companies.

Zohil, J. y M. Prijon (1999): The MED rule: The interdependence of container through-put and transhipment volumes in the Mediterranean ports, Maritime Policy \& Management, vol. 26, No 2, Londres, Taylor \& Francis Ltd.

Zona Franca de Iquique (2000): enero www.zofri.cl 